\title{
Diabetes potentiates acetylcholine-induced relaxation in rabbit renal arteries
}

\author{
José A. Alabadí ${ }^{\text {a, * }}$, Francisco J. Miranda ${ }^{\text {a }}$, Silvia Lloréns ${ }^{\text {a }}$, Rosa F. Ruiz de Apodaca ${ }^{\text {, }}$ \\ José M. Centeno a, Enrique Alborch ${ }^{\mathrm{a}, \mathrm{b}}$ \\ ${ }^{a}$ Departamento de Fisiología, Facultad de Farmacia, Universidad de Valencia, Avda. Vicent Andrés Estellés, s.n., 46100 Burjassot, Valencia, Spain \\ b Centro de Investigación, Hospital "La Fe", Valencia, Spain
}

Received 12 October 2000; received in revised form 5 February 2001; accepted 9 February 2001

\begin{abstract}
The response of rabbit renal arteries to acetylcholine and its endothelial modulation in diabetes were investigated. Acetylcholine induced concentration-related endothelium-dependent relaxation of renal arteries that was significantly more potent in diabetic rabbits than in control rabbits. Pretreatment with $N^{\mathrm{G}}$-nitro-L-arginine (L-NOArg), indomethacin, or L-NOArg plus indomethacin induced partial inhibition of acetylcholine-induced relaxation. Inhibition induced by L-NOArg plus indomethacin was significantly higher in arteries from diabetic rabbits than in arteries from control rabbits. In renal arteries depolarised with $\mathrm{KCl} 30 \mathrm{mM}$ and incubated with L-NOArg plus indomethacin, acetylcholine-induced relaxation was almost abolished in both groups of rabbits and this response was not different from that obtained in arteries without endothelium. Sodium nitroprusside induced concentration-dependent relaxation of renal arteries from control and diabetic rabbits without significant differences between the two groups of animals. These results suggest that diabetes potentiates the acetylcholine-induced relaxation in rabbit renal arteries. Increased release of nitric oxide and prostacyclin could be responsible for the enhanced relaxant potency of acetylcholine in diabetes. (C) 2001 Elsevier Science B.V. All rights reserved.
\end{abstract}

Keywords: Diabetes; Renal artery; Acetylcholine; Endothelium

\section{Introduction}

Impaired vascular function is one of the most important causes of morbidity and mortality in patients with diabetes mellitus. Both, macro- and microangiopathy contribute to the vascular deterioration associated with diabetes and lead to renal failure, blindness and neuropathy. The pathophysiological processes underlying vascular complications are still poorly understood. However, in recent years, several lines of evidence have suggested that some of the vascular changes in diabetes may be related to alterations in endothelial function (see, for review, Chan et al., 2000; De Vriese et al., 2000).

Endothelial cells are known to play a central role in the regulation of vascular tone both in physiological and pathophysiological conditions through the release of differ-

\footnotetext{
* Corresponding author. Tel.: +34-96-386-4904; fax: +34-96-3983395.

E-mail address: Jose.A.Alabadi@uv.es (J.A. Alabadí).
}

ent vasodilator and vasoconstrictor substances. Among these endothelial factors, nitric oxide (NO) is one of the most important mediators of vasodilation induced by different agonists. Endothelial cells synthesise NO from the amino acid $\mathrm{L}$-arginine by a $\mathrm{Ca}^{+2}$-dependent $\mathrm{NO}$ synthase (eNOS), which is expressed constitutively and activated by vasoactive agonists (see, for review, Moncada et al., 1991). It has been reported that in diabetes NO production and/or responsiveness of smooth muscle cells to NO are decreased (Sikorski et al., 1993; Taylor et al., 1995). In contrast, there are studies that have reported an enhanced production of NO (Choi et al., 1999) or an enhanced sensitivity of vascular smooth muscle cells to $\mathrm{NO}$ in diabetes (Yamada et al., 1995). It seems likely that prolonged exposure to hyperglycaemia may modulate the activity of the L-arginine-NO pathway in diabetes and that dysfunctions in NO synthesis or NO activity could lead to the abnormal endothelium-dependent relaxations observed in diabetes (Sobrevia and Mann, 1997; Chan et al., 2000).

Renal injury in diabetes is associated with vascular alterations. A considerable body of evidence indicates that 
endothelial dysfunction is closely associated with the development of diabetic nephropathy in humans (Stehouwer et al., 1997). It has been reported that the response of renal blood flow to reductions in renal perfusion pressure was markedly abnormal in diabetic rats (Mauer et al., 1990), which suggests that vasodilator factors may be abnormally active in diabetes (Tolins et al., 1993).

In the kidney, NO plays an important role in the regulation of renal hemodynamics not only in physiological conditions (Kone and Baylis, 1997), but also in diabetes (Komers et al., 2000). However, both increases (Shin et al., 2000) and decreases (Kamata and Yamashita, 1999) in NO synthesis have been reported in diabetic kidneys. Therefore, the role of NO in the renal vasodilation in diabetes remains controversial.

We have recently described changes in the endothelial regulatory mechanisms of the vascular responses of the carotid artery of diabetic rabbits (Miranda et al., 2000a,b). The present study was designed to investigate the effect of experimentally alloxan-induced diabetes on the endothelial mechanisms implicated in the relaxant response of isolated rabbit renal arteries to acetylcholine.

\section{Materials and methods}

Thirty-nine male New Zealand white rabbits were used in the present study. Animals were randomly divided into two experimental groups: twenty-one in the control group and eighteen destined for induction of experimental diabetes. Housing conditions and experimental procedures were in accordance with the European Union regulations on the use of animals for scientific purposes (86/609/EEC, Article 5, Appendix II) and promulgated by Spanish legislation on March 14, 1988 (R.D. 223 /1988).

\subsection{Induction of diabetes and control animals}

For induction of experimental diabetes, rabbits weighing $2.0-3.2 \mathrm{~kg}$ were sedated with intramuscular $40 \mathrm{mg}$ of ketamine $\left(\operatorname{Ketolar}^{\circledR}\right)$. Diabetes was induced by injecting alloxan (100 $\left.\mathrm{mg} \mathrm{kg}^{-1}\right)$ into the lateral ear vein. To prevent hypoglycaemia, $10 \mathrm{ml}$ of $5 \%$ glucose was injected (i.v.) after the alloxan and drinking water was supplemented with $10 \%$ glucose for the first $24 \mathrm{~h}$ after the alloxan injection. Thereafter, the animals were maintained on tap water and regular food ad libitum for 6 weeks. A second group of rabbits $(2.1-3.1 \mathrm{~kg})$ was maintained under the same conditions for the same time period to serve as age-matched controls (henceforth, "control rabbits"). Diabetic rabbits showed a marked increase in serum glucose and a failure to increase their body weight when compared with control rabbits. Table 1 shows the mean values of body weight and glycaemia before and 6 weeks after
Table 1

Values of body weight and glycaemia in control and diabetic rabbits

\begin{tabular}{lccc}
\hline & Body weight $(\mathrm{kg})$ & Glycaemia $(\mathrm{mM})$ & $n$ \\
\hline Control rabbits & & & \\
Initial time & $2.60 \pm 0.07$ & $5.9 \pm 0.2$ & 21 \\
6 Weeks after & $3.60 \pm 0.06$ & $6.1 \pm 0.2$ & 21 \\
& & & \\
Diabetic rabbits & & $5.8 \pm 0.2$ & 18 \\
initial time & $2.63 \pm 0.06$ & $20.8 \pm 0.9^{\mathrm{a}}$ & 18 \\
6 Weeks after & $3.02 \pm 0.07^{\mathrm{a}}$ & & \\
\hline
\end{tabular}

Results are means \pm S.E.M. for "n" rabbits.

${ }^{\mathrm{a}}$ Significantly different from corresponding value in control rabbits, $P<0.05$

diabetes induction for the rabbits in the diabetic group and for the rabbits in the control group.

\subsection{Isometric tension recording}

Six weeks after diabetes induction, the diabetic and the age-matched control rabbits were anaesthetised with sodium thiopental (sodium pentothal, 2\% i.v.), and killed by injection of potassium chloride $\left(10 \mathrm{mEq}, 0.5 \mathrm{ml} \mathrm{kg}^{-1}\right.$, i.v.) into the lateral ear vein. The renal arteries were dissected free and cut into cylindrical segments measuring $4 \mathrm{~mm}$ in length. Each segment was prepared for isometric tension recording in an organ bath. Two stainless steel L-shaped pins (diameter, $125 \mu \mathrm{m}$ ) were introduced through the arterial lumen. One pin was fixed to the organ bath wall and the other pin was connected to a strain gauge for isometric tension recording. The organ bath contained $5 \mathrm{ml}$ of Ringer-Locke solution that was bubbled continuously with $95 \% \mathrm{O}_{2}$ and $5 \% \mathrm{CO}_{2}$ to provide a $\mathrm{pH}$ of 7.3-7.4. Temperature was kept at $37^{\circ} \mathrm{C}$. A resting tension of $2 \mathrm{~g}$ was applied to the arterial segments, and they were allowed to equilibrate for a period of 60-90 min before the experiments were started. Tension was readjusted when necessary and the bath fluid was changed every $15 \mathrm{~min}$.

\subsection{Concentration-response curves}

The experiments were carried out with renal arteries from both control and diabetic rabbits. Concentration-response curves for acetylcholine $\left(10^{-9}-10^{-5} \mathrm{M}\right)$ were obtained cumulatively in renal arteries previously precontracted with 5-hydroxytryptamine (5-HT, $\left.10^{-5} \mathrm{M}\right)$. The active tone induced by 5 -HT in renal arteries from control rabbits $(3155 \pm 289 \mathrm{mg})$ was similar to that obtained in renal arteries from diabetic rabbits $(3417 \pm 306 \mathrm{mg})$. To assess the influence of the endothelium on the relaxation induced by acetylcholine, concentration-response curves were obtained with arteries from which the endothelium had been removed by rubbing the intimal surface with a scored stainless steel rod (rubbed arteries). The absence of endothelium was checked by silver staining. To assess the participation of NO in this relaxation, the concentration- 
response curves for acetylcholine were obtained after incubation $(20 \mathrm{~min})$ of the arteries with the inhibitor of $\mathrm{NO}$ synthase (NOS) $N^{\mathrm{G}}$-nitro-L-arginine (L-NOArg, $10^{-5}$ and $\left.10^{-4} \mathrm{M}\right)$. To examine the possibility that prostacyclin could mediate the relaxation induced by acetylcholine, the concentration-response curves were obtained after incubation $(20 \mathrm{~min})$ of the arteries with indomethacin $\left(10^{-5} \mathrm{M}\right)$, an inhibitor of cyclooxygenase. Moreover, to check the possibility that another factor different from NO or prostacyclin participated in this relaxation, concentration-response curves for acetylcholine were obtained in arteries preincubated $(20 \mathrm{~min})$ with the two inhibitors together, L-NOArg $\left(10^{-4} \mathrm{M}\right)$ plus indomethacin $\left(10^{-5} \mathrm{M}\right)$. Finally, concentration-response curves for acetylcholine were obtained in arteries depolarised with $\mathrm{KCl} 30 \mathrm{mM}$ and incubated with L-NOArg $\left(10^{-4} \mathrm{M}\right)$ plus indomethacin $\left(10^{-5}\right.$ M) to check whether this factor was the endothelium derived hyperpolarising factor (EDHF).

On the other hand, to detect the possible changes in the sensitivity of the vascular smooth muscle cells to NO, concentration-response curves for sodium nitroprusside $\left(10^{-9}-10^{-4} \mathrm{M}\right)$, a non-endothelium-dependent vasodilator, were obtained cumulatively in renal arteries from both control and diabetic rabbits, previously precontracted with 5-HT $10^{-5} \mathrm{M}$.

\subsection{Drugs and solutions}

Alloxan, 5-HT, acetylcholine, and indomethacin were obtained from Sigma, L-NOArg from Peptide Institute Inc and sodium nitroprusside from RBI. Alloxan was dissolved in saline solution. 5-HT, acetylcholine, and L-NOArg were dissolved in twice-distilled water and diluted in saline solution; the L-NOArg solution required sonication to dissolve completely. Indomethacin was dissolved in ethanol and diluted in saline solution. Sodium nitroprusside was dissolved and diluted in saline solution. Care was taken to protect sodium nitroprusside solutions from light due to its light sensitivity. The composition of the Ringer-Locke solution was (mM): $\mathrm{NaCl}, 120 ; \mathrm{KCl}, 5.4 ; \mathrm{CaCl}_{2}, 2.2$; $\mathrm{MgCl}_{2}, 1.0 ; \mathrm{NaHCO}_{3}, 25$; and glucose, 5.6. To prepare the $\mathrm{KCl}$-depolarising solution $(30 \mathrm{mM}), \mathrm{NaCl}$ was replaced by an equimolar amount of $\mathrm{KCl}$ in the normal RingerLocke solution.

\subsection{Statistical analysis}

Comparisons of body weight and glycaemia between control and diabetic rabbits were made by using unpaired Student's $t$-test. In the concentration-response curves, relaxation values are expressed as a percentage of the active tone. For each concentration-response curve, the maximum effect $\left(E_{\max }\right)$ and the concentration of the acetylcholine which produced half of $E_{\max }\left(\mathrm{EC}_{50}\right)$ were calculated. Maximum effects are expressed as means \pm standard error of the mean (S.E.M.) and $\mathrm{EC}_{50}$ as the geometric mean with its confidence limits $(95 \%)$ for repeated experiments. Statistical comparisons of $E_{\max }$ and $-\log \mathrm{EC}_{50}$ $\left(p \mathrm{D}_{2}\right)$ values between arteries from control and diabetic rabbits receiving the same experimental treatment were achieved by using unpaired Student's $t$-test. Comparisons between the values of $E_{\max }$ and $p \mathrm{D}_{2}$ of the concentration-response curves for acetylcholine obtained with the different treatments in the arteries from the control rabbits were made using ANOVA followed by the Newman-Keuls test. The same tests were used to compare the $E_{\max }$ and $p \mathrm{D}_{2}$ of the curves obtained with the different treatments in the arteries from diabetic rabbits. A probability value of less than $5 \%$ was considered significant.

\section{Results}

\subsection{Concentration-response curves for acetylcholine}

Cumulative addition of acetylcholine $\left(10^{-9}-10^{-5} \mathrm{M}\right)$ produced concentration-dependent relaxation of isolated renal arteries, previously contracted with 5-HT $10^{-5} \mathrm{M}$ (Fig. 1), and the $\mathrm{EC}_{50}$ was significantly lower in arteries from diabetic than from control rabbits, while there were no significant differences between the $E_{\max }$ values (Table 2). Mechanical removal of the endothelium strongly inhib-

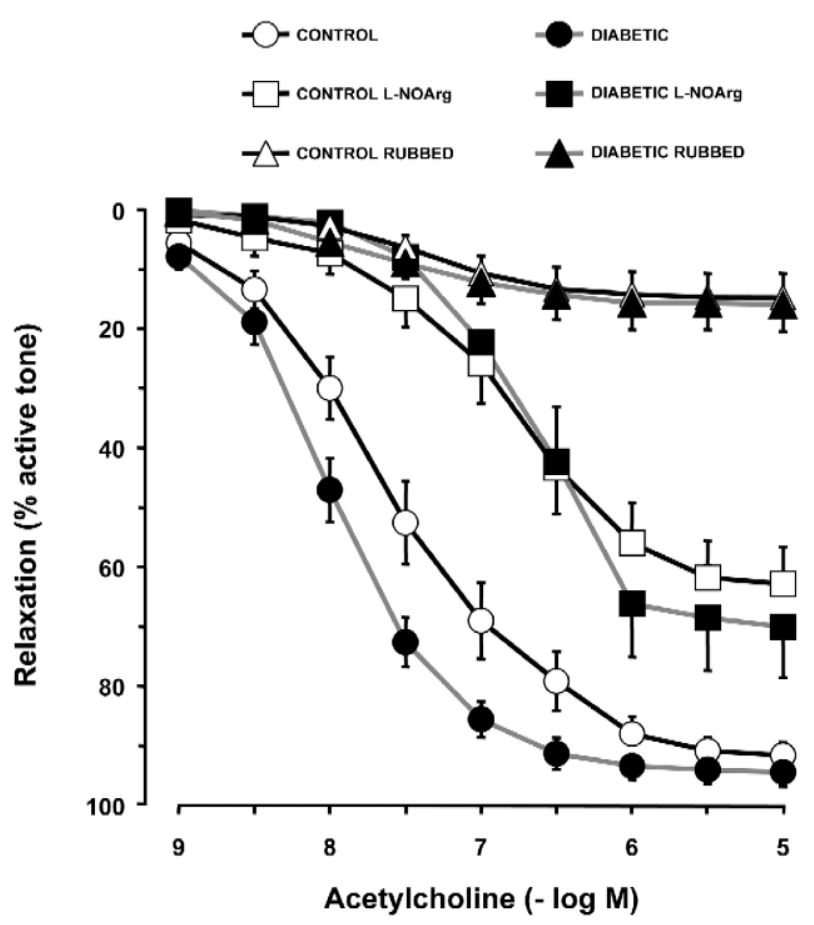

Fig. 1. Concentration-response relaxant curves for acetylcholine in isolated renal arteries from control (open symbols) and diabetic (solid symbols) rabbits in the following experimental conditions: control arteries, arteries incubated with $N^{\mathrm{G}}$-nitro-L-arginine $10^{-4} \mathrm{M}$ (L-NOArg) and arteries without endothelium (RUBBED). Relaxation values are expressed as percentage of the active tone induced by 5-hydroxytryptamine $10^{-5} \mathrm{M}$ and represent means \pm S.E.M. 
Table 2

$\mathrm{EC}_{50}$ and maximum effect $\left(E_{\max }\right)$ values, for concentration-response curves for acetylcholine in rabbit renal artery

\begin{tabular}{|c|c|c|c|}
\hline & $\mathrm{EC}_{50}(\mathrm{M})$ & $E_{\max }(\%)$ & $n$ \\
\hline \multicolumn{4}{|l|}{ Control rabbits } \\
\hline Control & $3.0(2.1-4.1) \times 10^{-8}$ & $92 \pm 2$ & 24 \\
\hline Rubbed & $4.5(3.0-6.8) \times 10^{-8}$ & $15 \pm 4^{\mathrm{a}}$ & 13 \\
\hline L-NOArg $10^{-5} \mathrm{M}$ & $6.8(4.7-9.8) \times 10^{-8}$ & $78 \pm 6^{\mathrm{b}}$ & 11 \\
\hline L-NOArg $10^{-4} \mathrm{M}$ & $1.5(1.1-2.1) \times 10^{-7 \mathrm{a}}$ & $63 \pm 6^{a, b}$ & 14 \\
\hline Indomethacin $10^{-5} \mathrm{M}$ & $9.1(6.9-12.0) \times 10^{-8 a}$ & $63 \pm 7^{\mathrm{a}, \mathrm{b}}$ & 15 \\
\hline $\begin{array}{l}\mathrm{L}-\mathrm{NOArg} 10^{-4} \mathrm{M}+ \\
\text { Indomethacin } 10^{-5} \mathrm{M}\end{array}$ & $4.9(3.5-6.9) \times 10^{-7 \mathrm{a}, \mathrm{b}, \mathrm{c}}$ & $53 \pm 8^{a, b}$ & 7 \\
\hline $\begin{array}{l}\mathrm{KCl}+\mathrm{L}-\mathrm{NOArg} 10^{-4} \mathrm{M}+ \\
\text { Indomethacin } 10^{-5} \mathrm{M}\end{array}$ & - & $9 \pm 2^{\mathrm{a}, \mathrm{c}, \mathrm{d}, \mathrm{e}}$ & 10 \\
\hline \multicolumn{4}{|l|}{ Diabetic rabbits } \\
\hline Control & $1.0(0.9-1.2) \times 10^{-8 f}$ & $95 \pm 2$ & 20 \\
\hline Rubbed & $3.3(2.0-5.4) \times 10^{-8 a}$ & $16 \pm 5^{\mathrm{a}}$ & 11 \\
\hline L-NOArg $10^{-5} \mathrm{M}$ & $4.3(3.2-5.6) \times 10^{-8 \mathrm{a}, \mathrm{c}, \mathrm{d}}$ & $86 \pm 5^{b}$ & 14 \\
\hline L-NOArg $10^{-4} \mathrm{M}$ & $2.3(1.8-3.0) \times 10^{-7 \mathrm{a}, \mathrm{b}}$ & $70 \pm 9^{a, b}$ & 11 \\
\hline Indomethacin $10^{-5} \mathrm{M}$ & $1.2(1.0-1.5) \times 10^{-7 a}$ & $73 \pm 6^{\mathrm{a}, \mathrm{b}}$ & 11 \\
\hline $\begin{array}{l}\mathrm{L}-\mathrm{NOArg} 10^{-4} \mathrm{M}+ \\
\text { Indomethacin } 10^{-5} \mathrm{M}\end{array}$ & $5.1(2.2-12.0) \times 10^{-7 a, b, c}$ & $28 \pm 5^{\mathrm{a}, \mathrm{c}, \mathrm{d}, \mathrm{f}}$ & 8 \\
\hline $\begin{array}{l}\mathrm{KCl}+\mathrm{L}-\mathrm{NOArg} 10^{-4} \mathrm{M}+ \\
\text { Indomethacin } 10^{-5} \mathrm{M}\end{array}$ & - & $7 \pm 2^{\mathrm{a}, \mathrm{c}, \mathrm{d}, \mathrm{e}}$ & 11 \\
\hline
\end{tabular}

$E_{\max }$ values are expressed as a percentage of active tone induced with 5-Hydroxytryptamine $10^{-5} \mathrm{M}$, except in the " $\mathrm{KCl}+\mathrm{L}-\mathrm{NOArg}+$ Indomethacin" groups in which active tone was induced with $\mathrm{KCl} 30$ $\mathrm{mM}$.

$\mathrm{EC}_{50}$ values are means and confidence limits; $E_{\max }$ values are means \pm S.E.M. L-NOArg: $N^{\mathrm{G}}$-nitro-L-arginine.

${ }^{a}$ Significantly different from corresponding control value, $P<0.05$.

${ }^{\mathrm{b}}$ Significantly different from corresponding rubbed value, $P<0.05$.

${ }^{\mathrm{c}}$ Significantly different from corresponding "Indomethacin $10^{-5} \mathrm{M}$ " value, $P<0.05$.

"Significantly different from corresponding "L-NOArg $10^{-4}$ M" value, $P<0.05$.

${ }^{\mathrm{e}}$ Significantly different from corresponding "L-NOArg $10^{-4} \mathrm{M}+$ Indomethacin $10^{-5} \mathrm{M}$ " value, $P<0.05$.

${ }^{\mathrm{f}}$ Significantly different from corresponding value in control rabbits, $P<0.05$.

ited the relaxant response to acetylcholine in arteries from both experimental groups of rabbits (Fig. 1). There were no significant differences between concentration-response curves for acetylcholine in rubbed arteries from control rabbits and those from diabetic rabbits (Table 2).

In arteries from control rabbits, incubation with $\mathrm{L}^{-}$ NOArg $10^{-5} \mathrm{M}$ did not significantly modify either the $\mathrm{EC}_{50}$ or the $E_{\max }$ in the concentration-response curves for acetylcholine. However, incubation of renal arteries from diabetic rabbits with the same concentration of L-NOArg significantly inhibited the relaxant potency of acetylcholine, without modifying the $E_{\max }$ value (Table 2).

Incubation with a higher concentration of L-NOArg $\left(10^{-4} \mathrm{M}\right)$ induced a significant inhibition of relaxant response to acetylcholine in renal arteries from both control and diabetic rabbits (Fig. 1; Table 2). There were no significant differences between $\mathrm{EC}_{50}$ and $E_{\max }$ values of concentration-response curves for acetylcholine in arteries preincubated with L-NOArg $10^{-4} \mathrm{M}$ from control rabbits and those from diabetic rabbits (Table 2). Moreover, the inhibition of the relaxant response to acetylcholine produced by L-NOArg was significantly lower than that produced by the mechanical rubbing of the arterial segments (Fig. 1; Table 2).

Pretreatment of isolated renal arteries with indomethacin $\left(10^{-5} \mathrm{M}\right)$ significantly inhibited the relaxant response to acetylcholine in arteries from either control or diabetic rabbits (Fig. 2; Table 2). Comparison of the concentration-response curves for acetylcholine in the presence of indomethacin did not show significant differences between either the $\mathrm{EC}_{50}$ or $E_{\max }$ values in arteries from control rabbits and those from diabetic rabbits (Table 2). Moreover, the inhibition of the relaxant response to acetylcholine produced by indomethacin was significantly lower than that produced by the mechanical rubbing of the arterial segments (Table 2).

When renal arteries were incubated with L-NOArg $\left(10^{-4}\right.$ M) and indomethacin $\left(10^{-5} \mathrm{M}\right)$ together, the inhibition of the relaxant response to acetylcholine was significantly greater in arteries from diabetic rabbits than in arteries from control rabbits (Fig. 3; Table 2). In renal arteries from control rabbits, the inhibition of relaxant response to acetylcholine produced by the double treatment (L-NOArg plus indomethacin) was significantly lower than that produced by the mechanical rubbing of the endothelium (Table 2). On the other hand, in renal arteries from diabetic rabbits, the double treatment (L-NOArg plus indomethacin) induced a significantly greater inhibition of the relaxant response to acetylcholine than that induced by either treatment separately (Table 2).

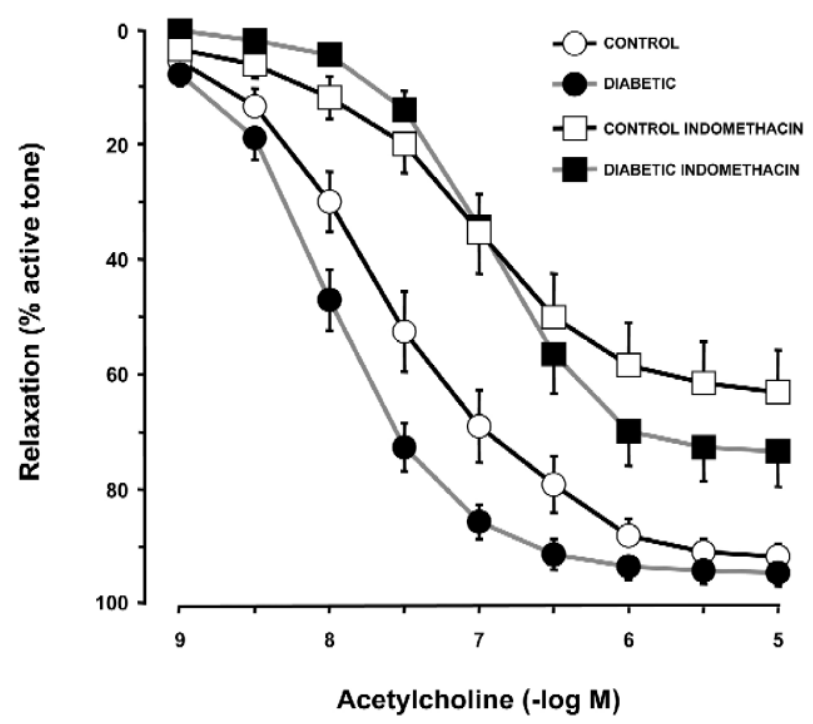

Fig. 2. Concentration-response relaxant curves for acetylcholine in isolated renal arteries from control (open symbols) and diabetic (solid symbols) rabbits in control conditions and incubated with indomethacin $10^{-5} \mathrm{M}$ (INDOMETHACIN). Relaxation values are expressed as percentage of the active tone induced by 5-hydroxytryptamine $10^{-5} \mathrm{M}$ and represent means \pm S.E.M. 
In renal arteries depolarised with $\mathrm{KCl} 30 \mathrm{mM}$ and incubated with L-NOArg $\left(10^{-4} \mathrm{M}\right)$ plus indomethacin $\left(10^{-5} \mathrm{M}\right)$, the relaxation induced by acetylcholine was almost abolished in both experimental groups of rabbits (Fig. 3). There were no significant differences between this treatment $(\mathrm{KCl}+\mathrm{L}-\mathrm{NOArg}+$ indomethacin $)$ and the effect produced by the mechanical rubbing of the arterial segments either in control or diabetic rabbits (Table 2). Moreover, with the latter treatment $(\mathrm{KCl}+\mathrm{L}-\mathrm{NOArg}+$ indomethacin), the inhibition of the relaxant response to acetylcholine was significantly greater than that produced by the double treatment (L-NOArg + indomethacin) both in control and diabetic rabbits (Fig. 3; Table 2).

Table 2 summarizes the $E_{\max }$ and $\mathrm{EC}_{50}$ values of concentration-response curves for acetylcholine under the different experimental conditions.

\subsection{Concentration-response curves for sodium nitroprus- side}

Cumulative addition of sodium nitroprusside $\left(10^{-9}\right.$ $\left.10^{-4} \mathrm{M}\right)$ produced concentration-dependent relaxation of isolated renal arteries previously contracted with 5-HT $10^{-5} \mathrm{M}$ from both control and diabetic rabbits (Fig. 4). In renal arteries from control rabbits, the $\mathrm{EC}_{50}$ value was 8.7 $(6.8-11.2) \times 10^{-8} \mathrm{M}$ and the $E_{\max }$ value was $99 \pm 1 \%$ of the active tone $(n=9)$. In renal arteries from diabetic rabbits, the $\mathrm{EC}_{50}$ value was $7.4(5.1-10.7) \times 10^{-8} \mathrm{M}$ and

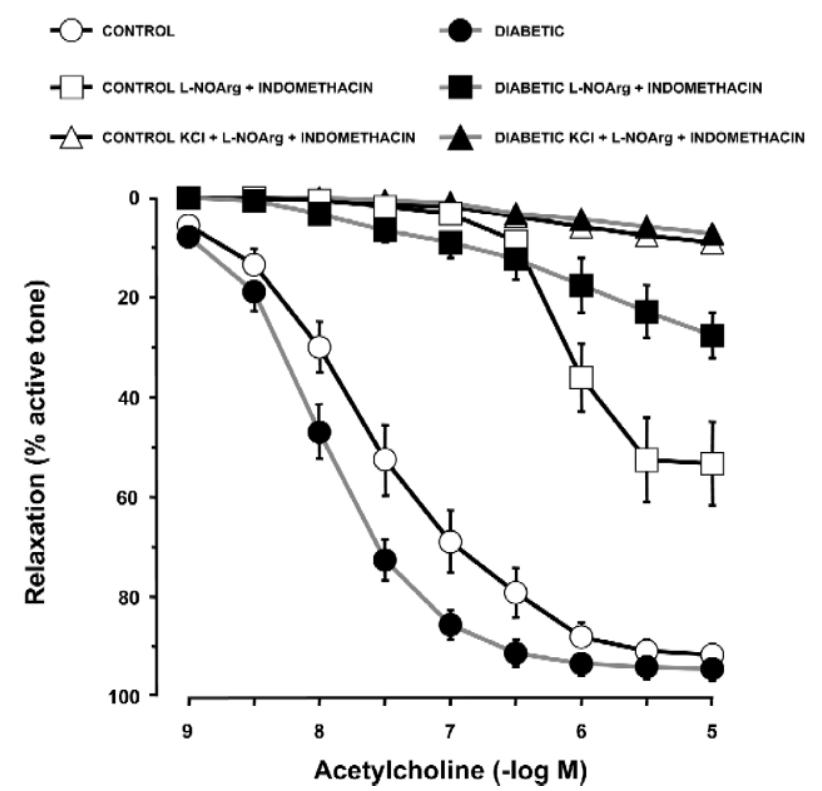

Fig. 3. Concentration-response relaxant curves for acetylcholine in isolated renal arteries from control (open symbols) and diabetic (solid symbols) rabbits in the following experimental conditions: control arteries (active tone induced by 5-hydroxytryptamine $10^{-5} \mathrm{M}$ ), arteries precontracted with 5-hydroxytryptamine $10^{-5} \mathrm{M}$ and incubated with $N^{\mathrm{G}}$-nitroL-arginine $10^{-4} \mathrm{M}$ plus indomethacin $10^{-5} \mathrm{M}$ (L-NOArg + INDOMETHACIN), and arteries precontracted with $\mathrm{KCl} 30 \mathrm{mM}$ and incubated with $N^{\mathrm{G}}$-nitro-L-arginine $10^{-4} \mathrm{M}$ plus indomethacin $10^{-5} \mathrm{M}$ $(\mathrm{KCl}+\mathrm{L}-\mathrm{NOArg}+\mathrm{INDOMETHACIN})$. Relaxation values are expressed as percentage of the active tone and represent means \pm S.E.M.

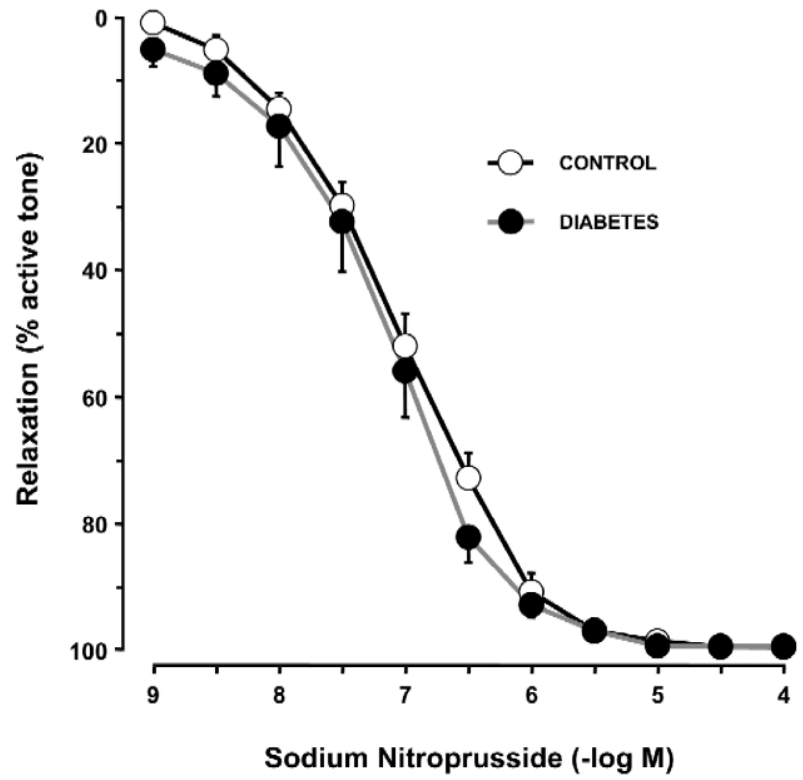

Fig. 4. Concentration-response relaxant curves for sodium nitroprusside in isolated renal arteries from control (open symbols) and diabetic (solid symbols) rabbits. Relaxation values are expressed as percentage of the active tone induced by 5-hydroxytryptamine $10^{-5} \mathrm{M}$ and represent means \pm S.E.M.

the $E_{\max }$ value was $99 \pm 1 \%$ of the active tone $(n=11)$. The $\mathrm{EC}_{50}$ and $E_{\max }$ values of the relaxation induced by sodium nitroprusside in diabetic rabbits were no significantly different with respect to those obtained in control rabbits.

\section{Discussion}

In the present study, the endothelium-dependent relaxation induced by acetylcholine was potentiated in renal arteries from alloxan-induced diabetic rabbits. Alloxan is a diabetogenic agent that induces a syndrome in animals that resembles type-I diabetes mellitus, characterised by hyperglycaemia, hypercholesterolaemia, glycosuria, and a raised level of glycosylated hemoglobin in erythrocytes (Agrawal et al., 1987), and it is commonly used as a valid experimental model of diabetes in the rabbit (Chan et al., 2000).

It is generally accepted that endothelium-dependent relaxation is impaired in different vascular beds of several animal species with experimentally induced diabetes mellitus, whereas this endothelium-mediated vasodilatation also appears impaired or unchanged in diabetic patients (see, for review, Sobrevia and Mann, 1997; Chan et al., 2000). However, there are some reports that show an enhanced endothelium-dependent relaxation in response to histamine (White and Carrier, 1986) and to acetylcholine (Bhardwaj and Moore, 1988; Omer et al., 1999) in diabetes.

Our results show that acetylcholine-induced relaxation of renal arteries from diabetic rabbits was significantly more potent than that obtained in arteries from control 
rabbits, with no significant changes in $E_{\max }$ values. These results are consistent with data obtained in renal arteries from diabetic dogs (Gebremedhin et al., 1989), and in perfused kidneys from diabetic rats (Bhardwaj and Moore, 1988). Therefore, it could be hypothesised that the renal vascular bed responds in a paradoxical fashion during diabetes, with an enhanced endothelium-dependent relaxation to acetylcholine. This enhanced relaxation could contribute to the renal hyperperfusion and hyperfiltration observed in diabetes (Tolins et al., 1993; Sugimoto et al., 1998).

In the present study, mechanical removal of the endothelium almost abolished the acetylcholine-induced relaxation both in control and diabetic rabbits, thus indicating the endothelium dependence of this arterial response. Moreover, L-NOArg, indomethacin, and L-NOArg plus indomethacin partially inhibited the acetylcholine-induced relaxation, whereas this relaxation was almost abolished when renal arteries both in control and diabetic rabbits, were depolarised with $\mathrm{KCl} 30 \mathrm{mM}$ and incubated with L-NOArg plus indomethacin. These results indicate that in rabbit renal arteries, acetylcholine-induced relaxation was mediated by three different endothelial factors both in control and diabetic animals: (1) NO; (2) a cyclooxygenase product, probably prostacyclin; and (3) EDHF. These findings confirm previous reports carried out in renal vascular bed of different species (Hayashi et al., 1994; Kagota et al., 1999).

On the other hand, our results show that the inhibitory effect of L-NOArg is greater in renal arteries from diabetic rabbits than in arteries from control rabbits. This is consistent with the greater impairment of acetylcholine-induced relaxation produced by L-NOArg in renal arteries from diabetic rats (Dai et al., 1993). Our result suggests that in renal arteries from diabetic rabbits the NO mediation of acetylcholine-induced relaxation is greater than in renal arteries from control rabbits, which could be the cause of the enhanced relaxant potency of acetylcholine in diabetes. Increased endogenous NO activity has been reported in kidneys from diabetic rats (Tolins et al., 1993). This increase could be due to enhanced NO synthesis (Sugimoto et al., 1998; Choi et al., 1999) and/or enhanced sensitivity of vascular smooth muscle to NO (Yamada et al., 1995). In our study, the latter hypothesis was ruled out because relaxation induced by the NO donor sodium nitroprusside is similar in renal arteries from control and diabetic rabbits. This result indicates that the sensitivity of smooth muscle cells of renal arteries to NO is not altered in our diabetic rabbits and, therefore, confirms the findings of other authors obtained in renal (García et al., 1999) and other vascular beds (Avogaro et al., 1997; Sheykhzade et al., 2000). In contrast, some authors have reported attenuated responses to nitrovasodilators in diabetic patients (Watts et al., 1996).

In human aortic endothelial cells, prolonged exposure to elevated concentrations of glucose increases eNOS gene, protein expression and NO release, thus indicating that both basal and stimulated production of NO are enhanced in high glucose-treated cells (Cosentino and Lüscher, 1998). In diabetic rats, an enhancement of NO synthesis by eNOS has been reported in afferent arterioles and glomeruli (Sugimoto et al., 1998). Enhanced expression of endothelial and neuronal isoforms of NOS in outer medulla (Shin et al., 2000), and increased expression of the three isoforms of NOS in the renal cortex (Choi et al., 1999) have also been described in diabetes. In addition, increased NO synthesis in diabetes was found by measuring increases in plasma and urinary excretion of nitrites and nitrates, the stable metabolites of NO (Choi et al., 1999; Shin et al., 2000). Moreover, it has been suggested that this enhanced NO activity could contribute to the excessive renal vasodilation observed in diabetes, which ultimately induces glomerular enlargement and glomerular hyperfiltration leading to diabetic nephropathy (Sugimoto et al., 1998; Choi et al., 1999).

In contrast with results obtained without indomethacin, in the presence of this inhibitor, there were no differences in the $\mathrm{EC}_{50}$ value of the acetylcholine-relaxant response between renal arteries from control and diabetic rabbits. This result suggests increased mediation of prostacyclin in the acetylcholine-induced relaxation of renal arteries from diabetic rabbits that could contribute to the enhanced vasorelaxant potency of acetylcholine observed in diabetes. This is consistent with the enhanced mediation by endogenous prostaglandins of the increased gastric and mesenteric blood flow observed in diabetic rats (Goldin et al., 1996) and with the increases in vasodilator prostanoid release in diabetic coronary arteries (Koltai et al., 1997). In addition, it has recently been reported that the renal production of prostacyclin is enhanced in diabetic rats (Okumura et al., 1999).

On the other hand, the inhibition of the acetylcholineinduced relaxation produced by double treatment (L-NOArg plus indomethacin) was significantly enhanced in renal arteries from diabetic rabbits. This lends support to the hypothesis of a greater participation of NO and prostacyclin that could contribute to the enhanced acetylcholine-relaxant potency observed in diabetes. Our finding also indicates that the participation of EDHF in the acetylcholine-induced relaxation of renal arteries from diabetic rabbits is lower than that observed in arteries from control rabbits. This is consistent with other studies showing an impairment of EDHF-mediated vasodilation (Fukao et al., 1997; Makino et al., 2000), and this decrease could constitute a compensatory mechanism meant to minimise the effects of the enhanced production of NO and prostacyclin.

In summary, the present study shows that diabetes potentiates the endothelium-mediated relaxant response to acetylcholine in renal arteries. In this vascular bed, the acetylcholine-induced relaxation is mediated by NO, a cyclooxygenase product, probably prostacyclin, and EDHF. The increased mediation of NO and prostacyclin observed 
in diabetes could be responsible for this enhanced relaxant potency of acetylcholine. These changes could contribute to the renal hyperperfusion and hyperfiltration observed in diabetic nephropathy.

\section{Acknowledgements}

The authors are grateful to Salvador Banacloche for his technical assistance.

\section{References}

Agrawal, D.K., Bhimji, S., Mcneill, J.H., 1987. Effect of chronic experimental diabetes on vascular smooth muscle function in rabbit carotid artery. J. Cardiovasc. Pharmacol. 9, 584-593.

Avogaro, A., Piarulli, F., Valerio, A., Miola, M., Calveri, M., Pavan, P., Vicini, P., Cobelli, C., Tiengo, A., Calo, L., Del Prato, S., 1997. Forearm nitric oxide balance, vascular relaxation, and glucose metabolism in NIDDM patients. Diabetes 46, 1040-1046.

Bhardwaj, R., Moore, P.K., 1988. Increased vasodilator response to acetylcholine of renal blood vessels from diabetic rats. J. Pharm. Pharmacol. 40, 739-742.

Chan, N.N., Vallance, P., Colhoun, H.M., 2000. Nitric oxide and vascular responses in type I diabetes. Diabetologia 43, 137-147.

Choi, K.C., Lee, S.C., Kim, S.W., Kim, N.H., Lee, J.U., Kang, Y.J., 1999. Role of nitric oxide in the pathogenesis of diabetic nephropathy in streptozotocin-induced diabetic rats. Korean J. Intern. Med. 14, $32-41$.

Cosentino, F., Lüscher, T.F., 1998. Endothelial dysfunction in diabetes mellitus. J. Cardiovasc. Pharmacol. 32 (Suppl. 3), S54-S61.

Dai, F.X., Diederich, A., Skopec, J., Diederich, D., 1993. Diabetes-induced endothelial dysfunction in streptozotocin-treated rats: role of prostaglandin endoperoxides and free radicals. J. Am. Soc. Nephrol. 4, 1327-1336.

De Vriese, A.S., Verbeuren, T.J., Van de Voorde, J., Lameire, N.H., Vanhoutte, P.M., 2000. Endothelial dysfunction in diabetes. Br. J. Pharmacol. 130, 963-974.

Fukao, M., Hattori, Y., Kanno, M., Sakuma, I., Kitabatake, A., 1997. Alterations in endothelium-dependent hyperpolarization and relaxation in mesenteric arteries from streptozotocin-induced diabetic rats. Br. J. Pharmacol. 121, 1383-1391.

García, V.M., Ochoa, J.E., Elias, M.M., 1999. Effect of early stage of experimental diabetes on vascular functions in isolated perfused kidneys. J. Auton. Pharmacol. 19, 97-103.

Gebremedhin, D., Koltai, M.Z., Pogatsa, G., Magyar, K., Hadhazy, P., 1989. Altered responsiveness of diabetic dog renal arteries to acetylcholine and phenylephrine: role of endothelium. Pharmacology 38, 177-184.

Goldin, E., Casadevall, M., Mourelle, M., Cirera, I., Elizalde, J.I., Panes, J., Casamitjana, R., Guth, P., Pique, J.M., Teres, J., 1996. Role of prostaglandins and nitric oxide in gastrointestinal hyperemia of diabetic rats. Am. J. Physiol. 270, G684-G690.

Hayashi, K., Loutzenhiser, R., Epstein, M., Suzuki, H., Saruta, T., 1994. Multiple factors contribute to acetylcholine-induced renal afferent arteriolar vasodilation during myogenic and norepinephrine- and $\mathrm{KCl}$-induced vasoconstriction. Studies in the isolated perfused hydronephrotic kidney. Circ. Res. 75, 821-828.

Kagota, S., Yamaguchi, Y., Nakamura, K., Kunitomo, M., 1999. Characterization of nitric oxide- and prostaglandin-independent relaxation in response to acetylcholine in rabbit renal artery. Clin. Exp. Pharmacol. Physiol. 26, 790-796.
Kamata, K., Yamashita, K., 1999. Insulin resistance and impaired endothelium-dependent renal vasodilatation in fructose-fed hypertensive rats. Res. Commun. Mol. Pathol. Pharmacol. 103, 195-210.

Koltai, M.Z., Hadhazy, P., Posa, I., Kocsis, E., Winkler, G., Rösen, P., Pogatsa, G., 1997. Characteristics of coronary endothelial dysfunction in experimental diabetes. Cardiovasc. Res. 34, 157-163.

Komers, R., Oyama, T.T., Chapman, J.G., Allison, K.M., Anderson, S., 2000. Effects of systemic inhibition of neuronal nitric oxide synthase in diabetic rats. Hypertension 35, 655-661.

Kone, B.C., Baylis, C., 1997. Biosynthesis and homeostatic roles of nitric oxide in the normal kidney. Am. J. Physiol. 272, F561-F578.

Makino, A., Ohuchi, K., Kamata, K., 2000. Mechanisms underlying the attenuation of endothelium-dependent vasodilatation in the mesenteric arterial bed of the streptozotocin-induced diabetic rat. Br. J. Pharmacol. 130, 549-556.

Mauer, S.M., Brown, D.M., Steffes, M.W., Azar, S., 1990. Studies of renal autoregulation in pancreatectomized and streptozotocin diabetic rats. Kidney Int. 37, 909-917.

Miranda, F.J., Alabadí, J.A., Llorens, S., Ruiz de Apodaca, R.F., Centeno, J.M., Alborch, E., 2000a. Influence of experimental diabetes on regulatory mechanisms of vascular response of rabbit carotid artery to acetylcholine. Life Sci. 66, 2071-2080.

Miranda, F.J., Alabadí, J.A., Llorens, S., Ruiz de Apodaca, R.F., Centeno, J.M., Alborch, E., 2000b. Diabetes-induced changes in endothelial mechanisms implicated in rabbit carotid arterial response to 5-hydroxytryptamine. Eur. J. Pharmacol. 401, 397-402.

Moncada, S., Palmer, R.M.J., Higgs, E.A., 1991. Nitric oxide: physiology, pathophysiology, and pharmacology. Pharmacol. Rev. 43, 109142.

Okumura, M., Imanishi, M., Yamashita, T., Yamamura, Y., Kim, S., Iwao, H., Tanaka, S., Fujii, S., 1999. Renal production of thromboxane and prostaglandins in a rat model of type 2 diabetes. Life Sci. 66 , 371-377.

Omer, S., Shan, J., Varma, D.R., Mulay, S., 1999. Augmentation of diabetes-associated renal hyperfiltration and nitric oxide production by pregnancy in rats. J. Endocrinol. 161, 15-23.

Sheykhzade, M., Dalsgaard, G.T., Johansen, T., Nyborg, N.C.B., 2000. The effect of long-term streptozotocin-induced diabetes on contractile and relaxation responses of coronary arteries: selective attenuation of CGRP-induced relaxations. Br. J. Pharmacol. 129, 1212-1218.

Shin, S.J., Lai, F.J., Wen, J.D., Hsiao, P.J., Hsieh, M.C., Tzeng, T.F., Chen, H.C., Guh, J.Y., Tsai, J.H., 2000. Neuronal and endothelial nitric oxide synthase expression in outer medulla of streptozotocin-induced diabetic rat kidney. Diabetologia 43, 649-659.

Sikorski, B.W., Hodgson, W.C., King, R.G., 1993. Effects of haemoglobin and $N$-nitro-L-arginine on constrictor and dilator responses of aortic rings from streptozotocin diabetic rats. Eur. J. Pharmacol. 242, 275282.

Sobrevia, L., Mann, G.E., 1997. Dysfunction of the endothelial nitric oxide signalling pathway in diabetes and hyperglycaemia. Exp. Physiol. $82,423-452$.

Stehouwer, C.D.A., Lambert, J., Donker, A.J.M., Van Hinsbergh, V.W.M., 1997. Endothelial dysfunction and pathogenesis of diabetic angiopathy. Cardiovasc. Res. 34, 55-68.

Sugimoto, H., Shikata, K., Matsuda, M., Kushiro, M., Hayashi, Y., Hiragushi, K., Wada, J., Makino, H., 1998. Increased expression of endothelial cell nitric oxide synthase (ecNOS) in afferent and glomerular endothelial cells is involved in glomerular hyperfiltration of diabetic nephropathy. Diabetologia 41, 1426-1434.

Taylor, P.D., Graves, J.E., Poston, L., 1995. Selective impairment of acetylcholine-mediated endothelium-dependent relaxation in isolated resistance arteries of the streptozotocin-induced diabetic rat. Clin. Sci. 88, 519-524.

Tolins, J.P., Shultz, P.J., Raij, L., Brown, D.M., Mauer, S.M., 1993. Abnormal renal hemodynamic response to reduced renal perfusion pressure in diabetic rats: role of NO. Am. J. Physiol. 265, F886-F895.

Watts, G.F., O’Brien, S.F., Silvester, W., Millar, J.A., 1996. Impaired 
endothelium-dependent and -independent dilatation of forearm resistance arteries in men with diet-treated non-insulin-dependent diabetes: role of dyslipidaemia. Clin. Sci. 91, 567-573.

White, R.E., Carrier, G.O., 1986. Supersensitivity and endothelium dependency of histamine-induced relaxation in mesenteric arteries isolated from diabetic rats. Pharmacology 33, 34-38.
Yamada, K., Nakano, H., Nakayama, M., Nozaki, O., Miura, Y., Nishimura, M., Tsuchida, H., Mimura, N., 1995. Endothelium-dependent relaxation in peripheral vasculature and kidney of non-insulin-dependent diabetes mellitus. J. Diabetes Complications 9, 203-207. 